\title{
Analysis of Nasal Bone Fractures: Etiological and Demographic Characteristics
}

\author{
KARAM A. ALLAM, M.D.; USAMA M. BAKRY, M.Sc. and AHMED G. ABDELMEGEED, M.D. \\ The Department of Plastic Surgery, Faculty of Medicine, Sohag University, Egypt
}

\begin{abstract}
Objective: The aim of this study was to assess the epidemiological and etiological characteristics of nasal fractures in the Southern region of Egypt during the study period and compare it to the literature.
\end{abstract}

Patients and Methods: A retrospective analysis of records of the patients who were presented to the Department of Plastic and Reconstructive Surgery (Sohag University Hospital) in the period from (November 2018 to October 2019) with traumatic nasal bone fractures (NBF). Demographic data such as age, sex, cause of injury, and relevant clinical data were all reviewed.

Results: Ninety-three patients with complete records fulfilled criteria and were included in this study. There was male predominance (83.9\%) with mean age of was $23.22 \pm 13.85$ years. Road traffic accident (RTA) was the main cause in $53.8 \%$, assault from others reported in $24.7 \%$ of the patients. Fractures due to falls were reported in $18.3 \%$ and $3.2 \%$ due to animal kick. $4.3 \%$ in the study population had septal hematoma. $28 \%$ of the patients had soft tissue lacerations on the nose. $16.1 \%$ had associated facial bone fractures. $2.2 \%$ had associated cranial injury. Associated systemic lesions were found in $20.4 \%$ of patients, with prevalence for injuries to the upper $(10.7 \%)$ and lower limbs $(6.5 \%)$.

Conclusion: The findings of this study revealed male predominance and RTA as main cause of NBF in southern Egypt. Epidemiological and etiological characteristics probably reveal the socioeconomic and cultural background of the study population.

Key Words: Fracture - Nasal bone - Trauma.

\section{INTRODUCTION}

Being the most prominent central part of the face, the nose is commonly exposed to trauma. Fractures of the nose are the commonest facial fractures forming almost $58 \%$ of the fractures of the facial skeleton $[\mathbf{1 , 2}]$. Causes of nasal bone fractures (NBFs) are variable and differ according to socioeconomic status, geographic areas, cultural and other factors [3].
NBFs are usually treated as outpatients' cases and considered minor injuries, $[4,5]$ though NBFs can result in significant cosmetic and functionaldeformity [6].

The nose has a unique anatomical framework formed of bone and cartilage and soft tissue. Nasal trauma can result in a variety of symptoms and signs from limited pain to severe epistaxis, long term sequalae and facial deformity, with variable post-operative patient satisfaction $[\mathbf{7 , 8 ]}$.

We conducted this study to review the etiology, demographics, and associated craniofacial and systemic trauma in patients with nasal fractures presented to Plastic and Reconstructive Surgery Department, Sohag University, Egypt during the study period.

\section{PATIENTS AND METHODS}

We collected and analyzed the records of patients who were presented to the Department of Plastic and Reconstructive Surgery (Sohag University Hospital) in the period from (November 2018 to October 2019) with traumatic nasal bone fractures. Patients were initially seen and assessed in the emergency (ER) department and later referred to the department of plastic surgery for further assessment. Demographic data such as age, sexwere reported. Etiology of the trauma was reviewed. Data regarding clinical evaluation of the patients (nasal fracture and lacerations, and associated craniofacial and systemic injuries, other clinical findings and complications) and further investigations were included.

We treated patients with NBFs as soon as possible if they come early before establishment of marked tissue edema. We used both general and local anesthesia according to patient's age and tolerance. 


\section{RESULTS}

Ninety-three patients with complete records fulfilled criteria and were included in this study. Patients characteristics revealed male predominance (83.9\%) (Fig. 1), with mean age of 23.22 \pm 13.85 years. The causes of the nasal fractures in this study are shown in Fig. (2). Road Traffic accidents (RTA) were the main cause in $53.8 \%$, whereas the second most frequent cause of fracture was assault from others, reported by $24.7 \%$ of the patients. Fractures due to falls were reported in $18.3 \%$ of patients. Three patients (3.2\%) had NBFs due to animal kick.

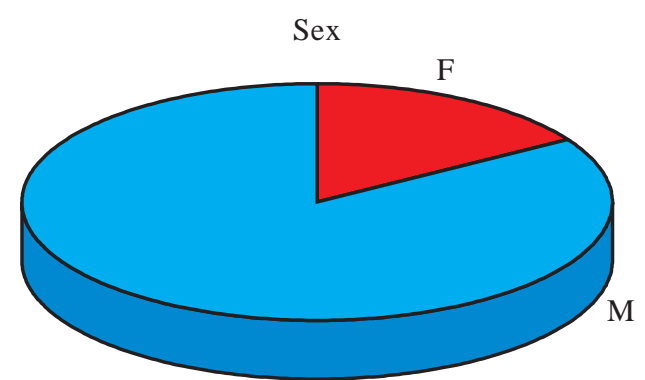

Fig. (1): Pie graph shows the sex distribution of the study patient population.

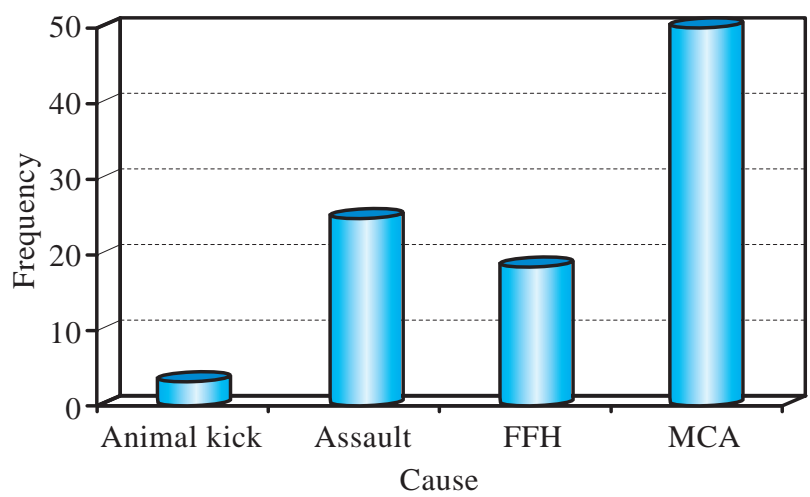

Fig. (2): Bar graph demonstrates the frequency of etiological factors of nasal fractures in our study.

Four patients $(4.3 \%)$ in the study population had septal hematoma. They were treated as immediate as possible to prevent serious complications such as infection, necrosis of the septal cartilage, and nasal deformity. Twenty-six of the patients $(28 \%)$ had soft tissue lacerations on the nose with or without extension to other facial units. Fifteen patients $(16.1 \%)$ had other associated facial bone fractures, with zygomatico-maxillary complex fractures $(n=6)$ (Fig. 3), orbital fractures $(n=4)$, and maxillary fractures $(n=3)$, being most frequent associations. Two patients $(2.2 \%)$ had associated cranial injury, where both had frontal sinus fracture that was treated conservatively (Fig. 4). Associated systemic lesions were found in $20.4 \%$ of patients, with prevalence of injuries to the upper $(10.7 \%)$ and lower limbs $(6.5 \%)$. Isolated nasal fractures were most noted in victims of direct violence (assault), while non-isolated fractures were seen more commonly in victims of road traffic accidents (RTAs).

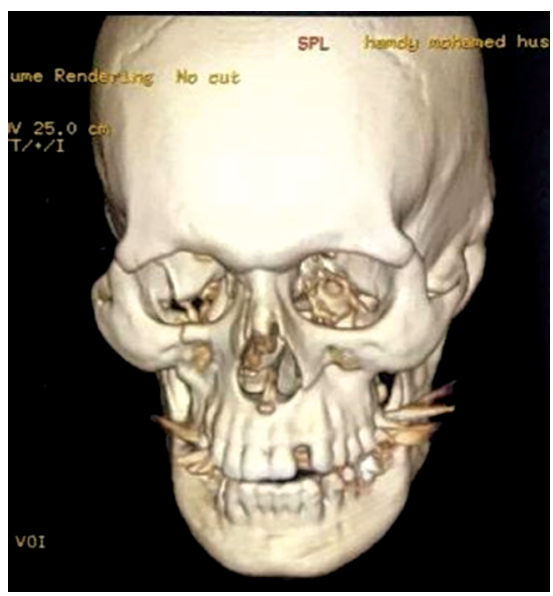

Fig. (3): 3D CT study shows right zygomaticomaxillary complex fracture associated with nasal fracture.

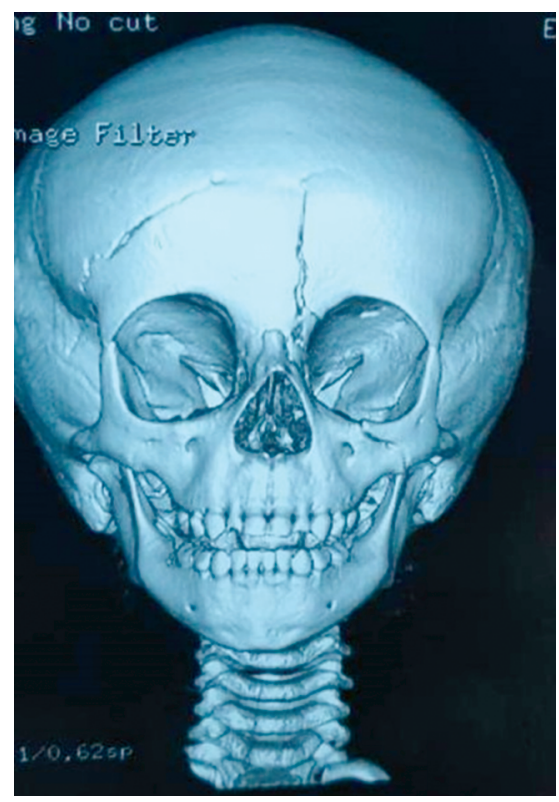

Fig. (4): 3D CT study shows frontal bone fracture associated with nasal fracture.

Full clinical examination was found carefully performed to assess the nasal bone fracture and other bony or soft tissue trauma of the face including nasal and oral cavities and eye examination. Radiological study was part of the initial assessment performed in the ER department. Imaging studies included X-ray and CT scan as needed. Facial Xray examination was performed for $40.8 \%$ of the patients, and CT scan of the facial bones was performed for $67.7 \%$ of the patients. Postoperative complications included residual deformity $(11.8 \%)$, 
olfactory disturbances (12.9\%), wound infection $(2.2 \%)$ and epistaxis in one patient $(1.1 \%)$. Three patients $(3.2 \%)$ had rhinoplasty to correct external nasal deformity and/or septal deviation.

Nasal fracture type was closed in most patients $(72 \%)$ and open in $(28 \%)$. NBF were predominantly simple fractures $(95.7 \%)$, comminution was reported in 4 patients only. Closed reduction was the main treatment used in 89 patients $(95.7 \%)$. Open reduction has been used in 4 patients with extensive fracture-dislocation of the nasal bones and septum.

\section{DISCUSSION}

This study was conducted to assess the demographics, etiology, and clinical findings in patients with nasal fractures presented to Department of Plastic Surgery, Sohag University during the study period. Road traffic accidents (RTA) were thecommonest reported cause of nasal fractures [9-

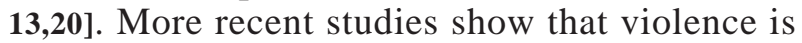
emerging as an overall most common cause $[13,14,17]$. This study showed motor car accident as the most common cause of nasal fractures $(53.8 \%)$, while violence (assault) represented the second common etiology $(24.7 \%)$. Other studies reported fall as a major frequent cause of NBFs [27]. In our study fall was the third common etiology $(18.3 \%)$. Sports trauma is a commonly reported etiology of nasal fractures in western literature, $[7,18]$ but none of our patients in this study had nasal fracture due to sport. Animal kick is among the rarely observed etiologies, [19] three patients in our study had their nasal fracture due to animal kick. This variability in frequencyof the etiologic background might be explained by the geographic location, patients' lifestyles, cultural backgrounds, socioeconomic and educational differences.

Regarding patient gender, literature shows male predominance. In an epidemiological analysis of 2881 patients with nasal bone fracturein a Chinese study, male to female ratio was found $2.44: 1.13$ Similar results were reported other reports [11,13,17]. In our study, male to female ratio was found to be higher than that (5.2:1). The significant male predominance might be explained by their involvement in hard physical work and overall outdoor activities [26]. Reports from other places sharing similar cultural and socioeconomic backgrounds showed similar results $[\mathbf{1 1}, \mathbf{1 4 , 1 5 , 1 6 ]}$.

We reported $15.1 \%$ associated other facial bone fractures. Chou et al., reported $17 \%$ concurrent facial bone fractures [11]. Zygomaticomaxillary complex, orbital and maxillary fractures were the most reported associated fractures in our patient population. Four patients $(4.3 \%)$ with septal hematoma were found in our study population, which is comparable to the findings reported by Ozgur et al., which found 4.76 incidence of the septal hematoma [20,21].

Diagnosis of isolated NBFs is mainly clinical andimaging studies rarely affect the treatment plan for those with an isolated nasal fracture [22,23]. Although, there is an increased trend towards use of radiological studies especially CT imaging for the work up of nasal fractures particularly during initial ER assessment of the patient [21,22]. Radiologic examination is usually required when other facial fractures are expected. X-rays have been used widely for imaging and diagnosis of nasal fractures for many years, [24] but its accuracy is limited in the diagnosisof nasal fractures (82\%), [23] CT is now preferred over X-rays for accurate assessment of facial fractures [11]. In our study, facial X-ray examination was performed for $40.8 \%$ of the patients, and CT scan of the facial bones was performed for $67.7 \%$ of the patients, mostly before referring patients from ER department to our service.

Early post-operative complications included nasal bleeding in one patient who was adequately managed by nasal pack and wound infection in two patients who were presented with soft tissue laceration. Other sequelae included residual external deformity (11.8\%) and olfactory disturbances $(12.9 \%)$. Three patients $(3.2 \%)$ had rhinoplasty to correct external nasal deformity and/or septal deviation. Forty full papers discussing treatment of nasal fractures were systematically reviewed, results showed an overall deformity rate was $10.4 \%$ $\pm 4.8 \%$, while $29(37.7 \% \pm 11.3 \%)$ complained of olfactory disturbances [18]. These findings may be under-reported in our study population because of the patients' degree of compliance and complaint during regular follow-up visits.

Closed reduction under general or local anesthesia was our preferred treatment option for isolated NBFs unless the nasal pyramid and septum are markedly displaced and integrity of nasal skeleton can only be established with open reduction. James et al., conducted a 20 years systemic database analysis of NBFs and concluded that both closed and open reductions achieve good results both is function and cosmetic appearance [3].

\section{Conclusions:}

The findings of this study revealed male predominance and RTA as main cause of NBFs in southern Egypt. Epidemiological and etiological 
characteristics are comparable to mainstream of western literature in some aspects and different in others which may reveal the socioeconomic and cultural background of the study population.

\section{REFERENCES}

1- Hwang K., Ki S.J. and Ko S.H.: Etiology of Nasal Bone Fractures. J. Craniofac. Surg., 28 (3): 785-788, 2017.

2- Pham T.T., Lester E., Grigorian A., Roditi R.E. and Nahmias J.T.: National Analysis of Risk Factors for Nasal Fractures and Associated Injuries in Trauma. Craniomaxillofac Trauma Reconstr., 12 (3): 221-227, 2019.

3- Hwang K., You S.H., Kim S.G., et al.: Analysis of nasal bone fractures; a six-year study of 503 patients. J. Craniofac. Surg., 17: 261-264, 2006.

4- Borghese B., Calderoni D.R. and Passeri L.A.: Retrospective analysis of the approach to nasal fractures at Unicamp Clinical Hospital. Rev. Bras de Cir. Plast., 26: 608-612, 2011.

5- James J.G., Izam A.S., Nabil S., Rahman N.A. and Ramli R.: Closed and Open Reduction of Nasal Fractures. J. Craniofac. Surg., 31 (1): 22-26, 2020.

6- Plum A.W. and Harris T.M.: Intranasal midazolam for anxiolysis in closed reduction of nasal fractures in children. Int. J. Pediatr. Otorhinolaryngol., 79: 1121-1123, 2015.

7- Marston A.P., O'Brien E.K. and Hamilton G.S. $3^{\text {rd.: Nasal }}$ Injuries in Sports. Clin. Sports Med., 36: 337-353, 2017.

8- Byun I.H., Lee W.J., Roh T.S. and Hong J.W.: Demographic Factors of Nasal Bone Fractures and Social Reflection. J. Craniofac. Surg., 31 (1): 169-171, 2020.

9- Erdmann D., Follmar K.E., DeBruijn M., et al.: A retrospective analysis of facial fracture etiologies. Ann. Plast. Surg., 60: 398-403, 2008.

10- Abdullah W.A., Al-Mutairi K., Al-Ali Y., et al.: Patterns and etiology of maxillofacial fractures in Riyadh City, Saudi Arabia. Saudi Dent. J. [serial online], 25: 33-38, 2013.

11- Chou C., Chen C., Wu Y., et al.: Refinement treatment of nasal bone fracture: A 6-year study of 329 patients. Asian J. Surg., 38: 191-198, 2015.

12- Kelley B.P., Downey C.R. and Stal S.: Evaluation and reduction of nasal trauma. Semin Plast. Surg., 24: 339$347,2010$.

13- Zhang L., Sun Y., Wang P., Shi R. and Chen D.: [Epidemiological analysis of 2881 patients with nasal bone fracture]. Lin Chung Er Bi Yan Hou Tou Jing Wai Ke Za Zhi., 34 (3): 239-243, 2020

14- Sindi A., Abaalkhail Y., Malas M., Alghamdi A. and Joharji M.: Patients With Nasal Fracture. J. Craniofac. Surg., 31 (3): 275-277, 2020.

15- Brasileiro B.F. and Passeri L.A.: Epidemiological analysis of maxillofacial fractures in Brazil: A 5-year prospective study. Oral Surg. Oral Med. Oral Pathol. Oral Radiol. Endod., 102: 28-34, 2006.

16- Al-Khateeb T., Hamasha A.N., Almasri M., et al.: Evidencebased medicine oral and maxillofacial tumours in North Jordanian children and adolescents: A retrospective analysis over 10 years. Int. J. Oral Maxillofac. Surg., 32: 7883, 2003.

17- Carvalho T.B., Cancian L.R., Marques C.G., Piatto V.B., Maniglia J.V. and Molina F.D.: Six years of facial trauma care: An epidemiological analysis of 355 cases. Braz J. Otorhinolaryngol., 76 (5): 565-74, 2010.

18- Atighechi S. and Karimi G.: Serial nasal bone reduction: A new approach to the management of nasal bone fracture. J. Craniofac. Surg., 20: 49-52, 2009.

19- Aydin O.E., Tan O., Algan S., Kuduban S.D., Barin E.Z., Cinal H., Sarici M. and Avsar U.: Maxillofacial fracture experiences: A review of 152 cases. Eurasian J. Med., 44 (3): 141-3, 2012.

20- Hwang K., Yeom S.H. and Hwang S.H.: Complications of Nasal Bone Fractures. J. Craniofac. Surg., 28 (3): 803$805,2017$.

21- Logan M., O'Driscoll K. and Masterson J.: The utility of nasal bone radiographs in nasal trauma. Clin. Radiol., 49 (3): 192-4, 1994.

22- Nigam A., Goni A., Benjamin A. and Dasgupta A.R.: The value of radiographs in the management of the fractured nose. Arch. Emerg. Med., 10: 293-297, 1993.

23- Becker O.J.: Nasal fractures. Arch. Otolaryngol., 48: 344$361,1948$.

24- Hong H.S., Cha J.G., Paik S.H., et al.: High-resolution sonography for nasal fracture in children. AJR Am. J. Roentgenol., 188: 86-92, 2007.

25- Dawood M.R.: Epidemiological analysis of the nasal trauma. Int. J. Sci. Res., 5: 774-777, 2015.

26- Akdağ M., Dursun R., Gül A., et al.: RetrospectiveAnalysis of Nasal Fractures in the Emergency Clinic. JAEM, 13: 139-142, 2014.

27- Ozgur A., Selcuk A., Gurbuz D., et al.: Analysis of simple nasal bone fracture and the effect of it on olfactory dysfunction. KBB-Forum, 7 (2): 68-70, 2008. 